\title{
Muscle fibre excitability and resting membrane potential in hamster muscular dystrophy
}

\author{
J . A . R. LENMAN A N D M. T ULLE Y
}

From the Department of Medicine and Medical Physics Department, Ninewells Hospital and Medical School, Dundee

SUMMARY Measurements of resting potential carried out in vivo in the dystrophic hamster and also measurements of muscle excitability showed no difference between dystrophy and healthy animals.

In murine muscular dystrophy, dystrophic muscle fibres have been found to have a lowered resting membrane potential, to give rise to spontaneous electrical potentials, and to have an increased excitability both to mechanical and electrical stimulation (Lenman, 1963; McComas and Mossawy, 1965, 1966). Reduced resting membrane potentials have also been recorded in human dystrophia myotonica (Hofmann et al., 1966; McComas and Mrozek, 1968) and in limb-girdle and facio-scapulo-humeral muscular dystrophy (Ludin, 1970). In 1975 Harris and Ward in a study of excised muscle from the hamster with genetic muscular dystrophy, which was first described in 1962 by Homburger and his associates, found a small reduction in resting membrane potential together with a reduced maximal rate of rise and overshoot amplitude of the action potentials in dystrophic muscle. In the present study we have recorded the resting membrane potential in vivo and also measured the excitability of muscle fibres in the dystrophic hamster.

\section{Methods}

Genetically dystrophic Syrian hamsters originating from the inbred strain described first by Homburger et al. (1962) and bred locally were used. Control animals were albino hamsters obtained from the Coomberhurst Breeding Establishment at Basingstoke. The animals varied in age from 22 to 26 weeks, and comparative measurements were made on control animals of comparable age. The animals were anaesthetised with pentobarbitone, and the exposed muscles of the right hind

Address for rcprint requests: Dr J. A. R. Lenman, Department of Medicine, Ninewells Hospital, Dundee DD1 9SY.

Accepted 10 March 1979 limb placed in a bath containing Lillie's solution at $35^{\circ} \mathrm{C}$. Glass microelectrodes filled with 2 molar $\mathrm{KCl}$ were used to record intracellular potential changes. To record the resting membrane potential electrodes were used which had a resistance of greater than 5 megohms and tip potentials of less than 5 millivolts. Potentials were amplified by a miniature differential DC preamplifier (F. Haer) and displayed on a Tektronix 502A oscilloscope. Membrane potential was measured using a circuit similar to that described previously (Lenman, 1963), but the electrode resistance was monitored continuously by a square pulse derived from a Digitimer. Only superficial cells were studied, and the resting potential was determined by applying a calibrating voltage in opposite sense to the membrane potential after each penetration. To determine the current necessary to excite the cell the fibres were stimulated through the recording electrode using a bridge circuit modified from that first described by Beranek (1964) (Fig. 1). The experiments were carried out in the soleus, gastrocnemius, and anterior tibial muscles. At the end of each experiment the animal was killed, and a sample of muscle tissue was removed for histology. At the same time blood was taken and the creatine kinase level estimated by the colorimetric method described by Hughes (1962).

\section{Results}

The resting membrane potentials and the minimum current necessary to excite muscle fibres are shown in the Table. In none of the muscles studied was the resting membrane potential significantly lower in the dystrophic than in the healthy animals nor was there any significant difference 

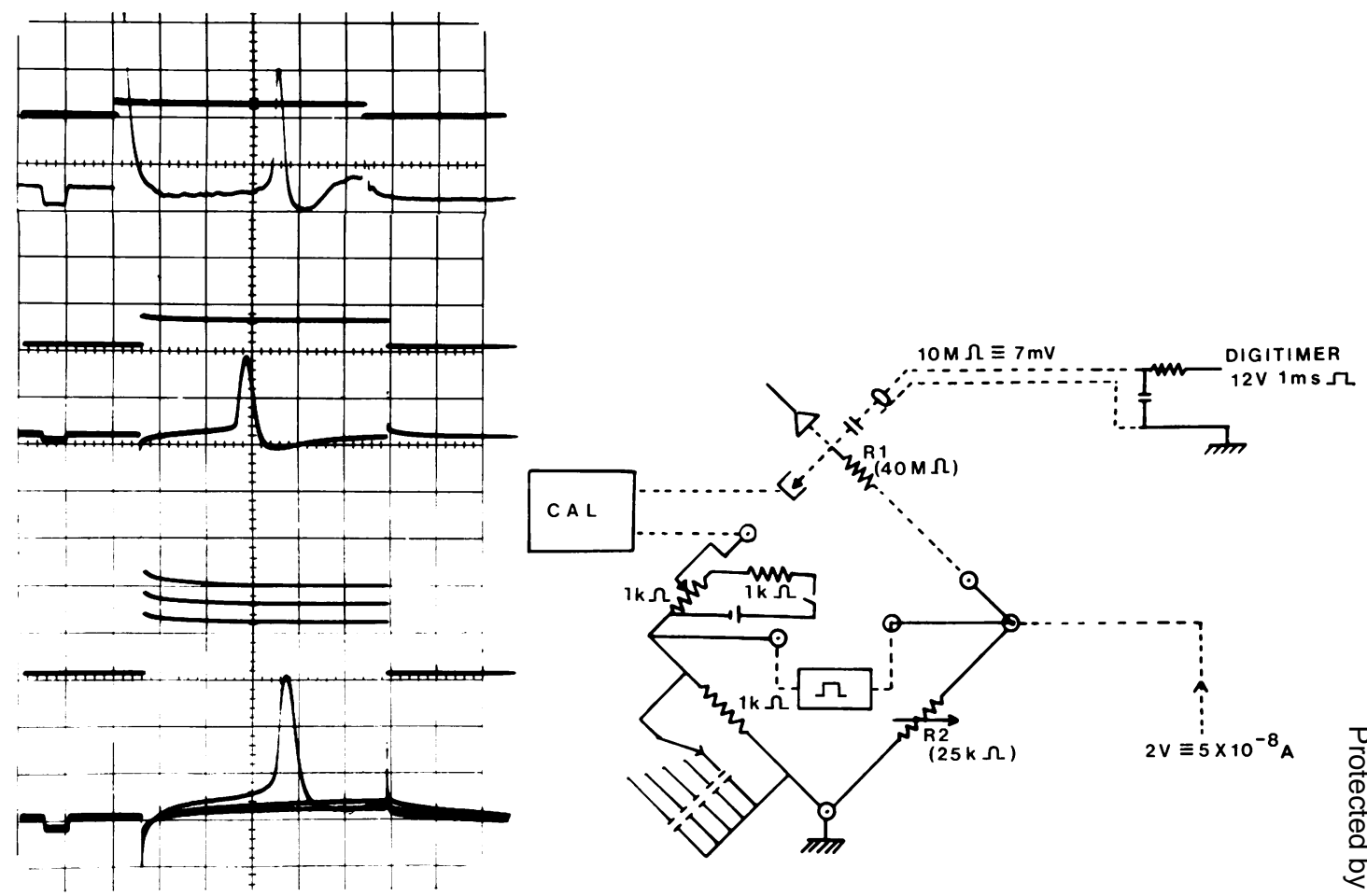

Fig. 1 Circuit arrangements to enable stimulating current to be applied through recording electrode (right). When bridge is balanced, potential across $R 2$ is equal to that across $R 1$ and a potential of 2 volts is equivalent to a current in recording electrode of $5 \times 10^{-8} \mathrm{~A}$. Upper trace on left shows action potential from dystrophic gastrocnemius, lower two traces from dystrophic soleus. Voltage calibration for upper sweep is $10 \mathrm{~mm}=20$ volts (upper trace), $10 \mathrm{~mm}=2$ volts (middle trace) and $10 \mathrm{~mm}=1$ volt (lower trace) so that in the three recordings the $10 \mathrm{~ms}$ stimulating pulses represent depolarising currents of $12.5 \times 10^{-8} \mathrm{~A}, 2.5 \times 10^{-8}$ $A$, and $11 \times 10^{-8}$ A respectively. Horizontal calibration is $10 \mathrm{~mm}=2 \mathrm{~ms}$. Square wave on lower sweep of each trace is derived from small current pulse to monitor electrode impedance.

Table Healthy and dystrophic hamster mean resting membrane potential and mean depolarising current

\begin{tabular}{lllllllll}
\hline Animal & $\begin{array}{l}\text { Number of } \\
\text { insertions }\end{array}$ & $\begin{array}{l}\text { Mean resting } \\
\text { potential }(\mathrm{mV})\end{array}$ & $S D$ & $S E$ & $\begin{array}{l}\text { Number of } \\
\text { insertions }\end{array}$ & $\begin{array}{l}\text { Mean } \\
\text { stimulating } \\
\text { current } \\
\left(\times 10^{-8} A\right)\end{array}$ & $S D$ & $S E$ \\
\hline $\begin{array}{c}\text { Healthy hamster } \\
\text { (soleus) }\end{array}$ & 261 & 73.0 & 7.29 & 0.45 & 52 & 7.81 & 3.58 & 0.49 \\
$\begin{array}{c}\text { Dystrophic hamster } \\
\text { (soleus) }\end{array}$ & 250 & 75.1 & 8.12 & 0.51 & 53 & 9.54 & 6.10 & 0.84 \\
$\begin{array}{c}\text { Healthy hamster } \\
\text { (gastrocnemius) }\end{array}$ & 270 & 69.4 & 8.83 & 0.54 & 22 & 9.52 & 4.80 & 1.02 \\
$\begin{array}{c}\text { Dystrophic hamster } \\
\text { (gastrocnemius) }\end{array}$ & 307 & 70.6 & 10.73 & 0.61 & 34 & 11.06 & 4.75 & 0.81 \\
$\begin{array}{c}\text { Healthy hamster } \\
\text { (tib. ant.) }\end{array}$ & 65 & 67.8 & 6.74 & 0.84 & & & & \\
$\begin{array}{c}\text { Dystrophic hamster } \\
\text { (tib. ant.) }\end{array}$ & 85 & 67.6 & 8.91 & 0.97 & & & \\
\hline
\end{tabular}


between the minimum current necessary to excite the muscle between the two groups. Only for the gastrocnemius muscle was the scatter of values marginally wider in the dystrophic than in the healthy animals (Fig. 2). Histological features of the dystrophic muscles were similar to those described by Homburger et al. (1966) and included marked variation in muscle fibre size, central nuclei, and chains of internally rowed nuclei. The level of serum creatine kinase was higher in dystrophic animals (5950 IU, SE 417) than in control animals (1902 IU, SE 267) as previously described by Eppenberger et al. (1964). This is a significant difference $(P<0.001)$ but the absolute values are higher, as might be anticipated, since the blood specimens were obtained at the end of the experimental procedure.

\section{Discussion}

In this study we have not demonstrated the lowered resting membrane potential which has previously been recorded in several forms of human muscular dystrophy and in murine muscular dystrophy nor have we found the abnormal excitability of the muscle fibres which has been recorded in the dystrophic mouse (McComas and Mossawy, 1966). Only in the gastrocnemius muscle did the distribution of membrane potentials show a slightly wider range of values in the dystrophic than in the normal hamster which compares with the very wide scatter of values seen in the dystrophic mouse (Lenman, 1965). In a study of excised muscle in the hamster Harris and Ward (1975) have found

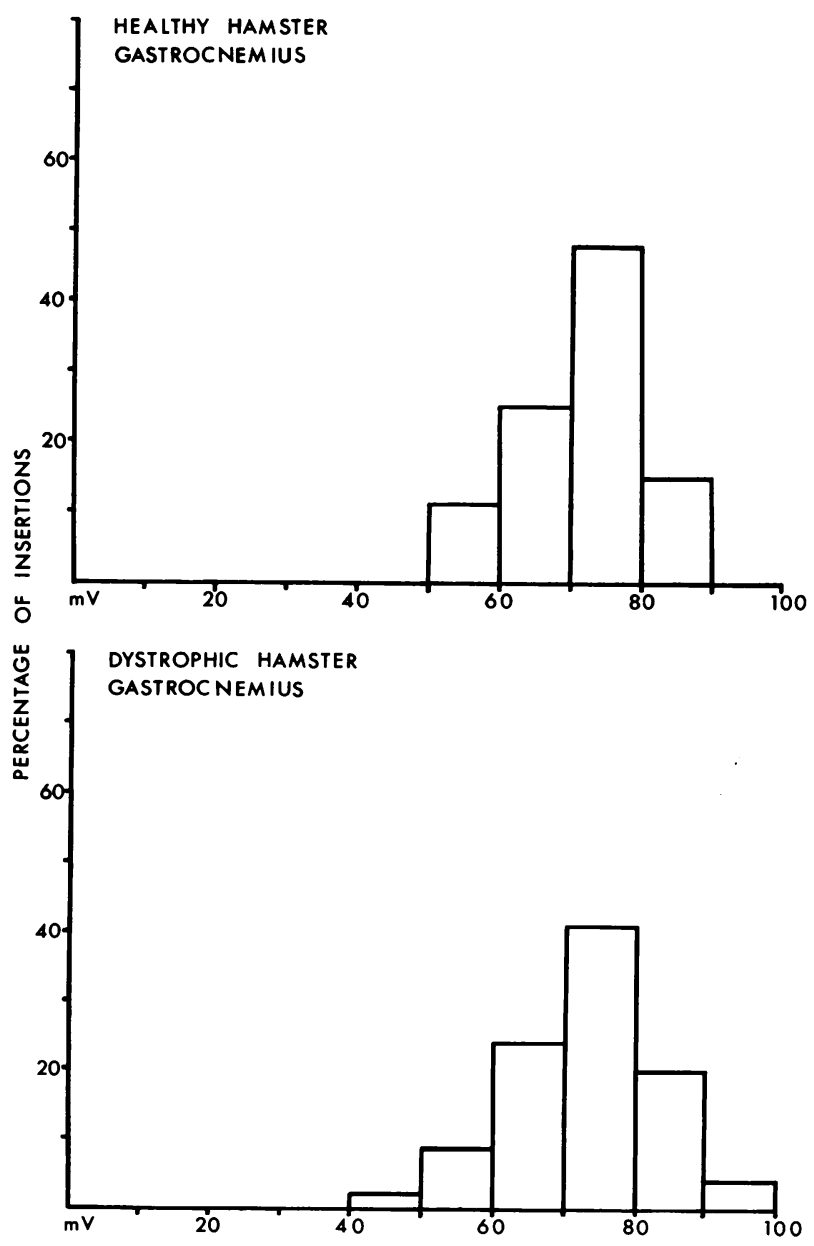

Fig. 2 Distribution of membrane potentials for healthy and dystrophic gastrocnemius muscles. 
a small but significant decrease in resting membrane potential in the dystrophic compared with normal animals. It is of interest, however, that in that study it was found in certain of the muscles that the lowered resting potentials were confined to parts of muscle which had apparently undergone atrophy, the "apparently normal muscle" having resting potentials within the normal range. If these "atrophic areas" represent either denervated or regenerating muscle our failure to find any reduction in resting membrane potential is difficult to reconcile with any significant degree of denervation being present. Our animals were considerably older than those used by Harris and Ward and it is a'so possible, as Neerunjun and Dubowitz (1974) have suggested, that the dystrophic animals which in the hamster are already affected by a relatively mild condition may be tending to become more normal through gradual removal of the dystrophic gene from the gene pool by continuous inbreeding. On the other hand, the presence of definite histological changes in our animals and of elevated serum enzymes would suggest that in our animals, notwithstanding their limited disability, the dystrophic process remains active. There is now abundant evidence that a defect in cell membranes is an important feature of muscular dystrophy (Mokri and Engel, 1975; Hull and Roses, 1976). It would appear, however, that although resting membrane potential and changes in membrane excitability are a frequent finding in muscular dystrophy they are not an essential feature of the dystrophic process.

It is a pleasure to acknowledge the technical assistance of Mrs Catherine Kinnear and Mrs Ann Donald.

\section{References}

Beranek, R. (1964). Intracellular stimulation electromyography in man. Electroencephalography and Clinical Neurophysiology, 16, 301-304.

Eppenberger, M., Nixon, C. W., Baker, J. R., and Homburger, F. (1964). Serum phosphocreatine kinase in hereditary muscular dystrophy and cardiac necrosis of Syrian golden hamsters Proceedings of the Society for Experimental Biology and Medicine, 117, 465-468.

Harris, J. B., and Ward, M. R. (1975). Some electrophysiological properties of isolated extensor digitorum longus muscles from normal and genetically-dystrophic hamsters. Experimental Neurology, 46, 103-114.
Hofmann, W. W., Alston, W., and Rowe, G. (1966). A study of individual neuromuscular junctions in myotonia. Electroencephalography and Clinical Neurophysiology, 21, 521-537.

Homburger, F., Baker, J. R., Nixon, C. W., and Wilgram, G. (1962). A new hereditary disease of Syrian hamsters: primary generalised polymyopathy and cardiac necrosis. Archives of Internal Medicine, 110, 660-662.

Homburger, F., Baker, J. R., Wilgram, G. F., Caulfield, J. B., and Nixon, C. W. (1966). Hereditary dystrophy-like myopathy. The histopathology of hereditary dystrophy-like myopathy in Syrian hamsters. Archives of Pathology, 81, 302-307.

Hughes, B. P. (1962). A method for the estimation of serum creatine kinase and its use in comparing creatine kinase and aldolase activity in normal and pathological tissue. Clinica Chimica Acta, 7, 597603.

Hull, K. L., and Roses, A. D. (1976). Stoichiometry of sodium and potassium transport in erythrocytes from patients with myotonic muscular dystrophy. Journal of Physiology, 254, 169-181.

Lenman, J. A. R. (1963). Micro-electrode studies in muscle disease. In Research in Muscular Dystrophy, Proceedings of the Second Symposium, pp. 230239. Pitman: London.

Lenman, J. A. R. (1965). Effect of denervation on the resting membrane potential of healthy and dystrophic muscle. Journal of Neurology, Neuro surgery, and Psychiatry, 28, 525-528.

Ludin, H. P. (1970). Microelectrode study ob dystrophic human skeletal muscle. Europeap Neurology, 3, 116-121.

McComas, A. J., and Mossawy, S. J. (1965). Electro? physiological investigation of normal and dystrophic muscles in mice. In Research in Muscular Dystrophy, Proceedings of the Third Symposium, pp. 317-341. Pitman: London.

McComas, A. J., and Mossawy, S. J. (1966). Excitability of muscle fibre membranes in dystrophic mice. Journal of Neurology, Neurosurgery, and Psychiatry, 29, 440-445.

McComas, A. J., and Mrozek, K. (1968). The electrical properties of muscle fibre membranes in dystrophia myotonica and myotonia congenita. Journal of Neurology, Neurosurgery, and Psychiatry, 31, 441-447.

Mokri, B., and Engel, A. G. (1975). Duchenne dystrophy: electron microscopic findings pointing to a basic or early abnormality in the plasma membrane of the muscle fiber. Neurology (Minneapolis), 25, 1111-1120.

Neerunjun, J. S., and Dubowitz, V. (1974). Muscle transplantation and regeneration in the dystrophic hamster. 1. Histological studies. Journal of the Neurological Sciences, 23, 505-519. 